Asian-Australasian Journal of

Food Safety and Security

ISSN 2523-1073 (Print) 2523-2983 (Online)

www.ebupress.com/journal/aajfss

\title{
Article \\ Assessment of nutritional status and other associated factors of lactating mother at Gangni Pauroshava in Meherpur district, Bangladesh
}

\author{
Md. Tanvir Islam ${ }^{1 *}$, Md. Ashrafuzzaman Zahid², Md. Ismail Hossain ${ }^{2}$ and Rashida Parvin ${ }^{2}$ \\ ${ }^{1}$ Department of PublicHealth, American International University-Bangladesh, Banani, Dhaka, Bangladesh \\ ${ }^{2}$ Department of Nutrition and Food Technology, Jessore University of Science and Technology, Jessore, \\ Bangladesh
}

*Corresponding author: Md Tanvir Islam, Department of Public Health, American International UniversityBangladesh, Banani, Dhaka, Bangladesh. E-mail: tetratul@gmail.com

Received: 07 November 2017/Accepted: 20 November 2017/ Published: 21 November 2017

\begin{abstract}
The present study was to provide information about the nutritional status of lactating women as well as proffer solutions that are aimed at improving maternal nutrition in the study area. The study area was Gangni union of Meherpur district. 105 exclusively breastfeeding women aged 16-35 years old were initially enrolled in the study. Of these study lactating women completed $24 \mathrm{~h}$ dietary recall food intake. The findings was about $16.2 \%$ lactating mothers were under 19 years, 53.3\% respondents were between the ages of 20-25 years, $23.8 \%$ respondents were between the ages of 26-30 years and $37.1 \%$ lactating mothers had completed primary education. About $95.2 \%$ respondents were housewife and $4.8 \%$ respondents were service holders. The finding was $56.2 \%$ respondents have one child and $38.1 \%$ respondents have 3 family members, $43.8 \%$ respondent has 4 family members. About $7.6 \%$ respondents are underweight, 55.2\% respondents are normal, $33.3 \%$ respondents are overweight and 3.8\% respondents are obese. Total 7.6\% respondents are underweight, $55.2 \%$ respondents are normal, 33.3\% respondents are overweight and 3.8\% respondents are obese where 5.7\% respondents under 19 year aged and $1.9 \%$ respondents over 30 year aged are underweight. About $40 \%$ respondents got surgerian delivery where $60 \%$ respondents got normal delivery. It was found that $100 \%$ respondents maintain hygiene such as washing hands before eating foods, washing hands after using bathroom, brushing teeth regularly, avoiding nasty foods etc.
\end{abstract}

Keywords: food; nutrition; maternal health; awareness

\section{Introduction}

Possessing a land area of 147570 square kilometers and over 16 million populations. Bangladesh is the ninth most populous country and one of the most densely populated countries in the world (BBS, 2003). Over population and poverty are omnipresent in Bangladesh and causing many types of population hazards and malnutrition is one of them. The high prevalence of under nutrition in Bangladesh is popularly attributed to a combination of extreme poverty, environmental insult and poor health. Specially, women are particularly vulnerable; suffering from social, economic and nutritional deprivation to a far greater extent than men (Giashuddin et al., 2003). The lactation period is a major source of concern in developing countries because of its positive impact on the health and nutrition of infants. Lactating women from developing countries are considered nutritionally vulnerable groups because this period places a high nutritional demand on the mother. Inadequate maternal diet during this period will lead to poor secretion of nutrients in breast milk and this can have long term impact on the child's health (Picciano, 2001; Marcos et al., 2003; Jones et al., 2010). A lactating woman should produce about 700 to $800 \mathrm{ml}$ of milk per day and this requires an extra energy need of about 500 calories per day (Sylvia and Mary, 2002). Women who are severely malnourished have reduced lactation performance (Allen, 2012), thus, the quantity of milk produced depends a lot on the mother's diet. The 
diet consumed by the mother will not only fulfill her own nutritional needs but will also enable her to produce enough milk for her infant. Nutritional status is an indication of the overall well-being of a population (Sylvia and Mary, 2002; Haileslassie et al., 2013). Lactation has different effects on maternal nutritional status depending on its duration, intensity, as well as cultural diversity (Rasmussen and McGuire, 1996). Breastfeeding when practiced either exclusively or otherwise had no significant negative effect on the nutritional status of the mothers (Sanusi and Falana, 2013). Irrespective of breastfeeding pattern, lactation also had no profound effect on maternal body composition (Ukegbu and Uwaegbute, 2012). However, the high energy cost of lactation as well as the nutritional and health risk it could pose for the woman emphasizes the need for continuous monitoring of their nutritional status and dietary intake in poor resource countries. South western part of the country observed poor dietary intakes among lactating women studied (Ijarotimi, 2010). Information regarding the nutritional status and dietary intake of lactating mothers in the study area is scarce. It is well known that lactating women should substantially increase their intake of dietary energy, protein and other nutrients. Because breastfed babies of separate ethnic groups living in the same area have different average weights and lengths (Chasnyk et al., 2011), there is a possibility that the actual intake of energy, protein and other nutrients may differ among different ethnicities. It is known that, compared with the total population, indigenous people as a rule experience more health related problems (Rakibul and Mashhood, 2010). The nutrient intake of lactating women is one of the most important determinants of women's health, well-being and the ability for long-term successful breastfeeding. Human lactation is a natural process, which is well established to provide many health benefits for both mothers and their infants. Lactation also has many favorable effects on women, including reducing the incidence of type 2 diabetes, metabolic syndrome (Gunderson et al., 2010; Stuebe et al., 2005), cardiovascular disease (Stuebe et al., 2010; Schwarz et al., 2009) and cancer (Stuebe et al., 2009). The nutrient intake of lactating women affects the nutrient content of breast-milk and maternal health (Lönnerdal, 1986). As noted, many essential nutrients are secreted into breast-milk and represent a significant proportion of nutrient intake in the maternal died, including docosahexaenoicacid (DHA) (Scopesi et al., 2001; Guesnet and Alessandri, 2011; Makrides et al., 1996), most vitamin including vitamin $\mathrm{B}_{2}$ (Bates et al., 1982), vitamin A (Haskell and Brown, 1999) and vitamin D (Mulligan et al., 2010; Hollis and Wagner, 2004). Thus nutritional requirements for lactating women are higher compared to women who do not breastfeed (Cheng et al., 2009; Dang et al., 2008). Perinatal health of the infants is closely linked to the well-being of mothers (Whitehead, 1979; Takimoto et al., 2003). The nutrients that infants receive from breast-milk, and the mother's overall physical and mental health during breastfeeding, are all factors that affect the baby's early health and will continue to influence their health into later life (Paul, 2010). Nutritional status and dietary pattern of lactating mother in Bangladesh is very poor. So, it was a common cause of child malnutrition. Millions of children are suffering from one or more forms of malnutrition, including low birth weight, stunting, underweight, and micronutrient deficiencies, especially vitamin A, iron, and iodine. Globally more than one third of the child deaths are attributable to malnutrition. Furthermore, maternal under-nutrition has also become a matter of great importance because of the fact that malnutrition in a child's life begins with the mother. Maternal undernutrition rate is measured by proportion of women who have Body Mass Index (BMI, weight in $\mathrm{kg}$ divided by height in meters squared) less than $18.5 \mathrm{~kg} / \mathrm{m}^{2}$ It is strongly related to the delivery of low-birth weight babies. Although maternal under-nutrition has decreased in Bangladesh during the last decade, from 53\% in 1996/97 to $32 \%$ in 2005 , it is still a matter of concern to ensure a healthy future generation. This survey is an attempt to identify the current nutritional status and consumption pattern of the vulnerable group including lactating mother in the selected areas of Bangladesh. Information on their dietary pattern and nutrition awareness will provide a picture of the prevailing daily food intake pattern and nutritional status of the rural area of Bangladesh. So this can be used as a tool to take integrated interventional program to achieve sustainable food security and therefore, improvement of nutritional status of the nation. The objective of this study was therefore to provide information about the nutritional status of lactating women as well as proffer solutions that are aimed at improving maternal nutrition in the study area.

\section{Materials and Methods}

\subsection{Study area}

The study area was Gangni union of Meherpur district. It is located in between $23^{\circ} 49^{\prime}$ and $23^{\circ} 81^{\prime}$ north latitudes and in between $88^{\circ} 45.3^{\prime}$ and $88^{\circ} 75.5^{\prime}$ east longitudes (Figure 1). 105 exclusively breastfeeding women aged 16-35 years old were initially enrolled in the study. Of these study lactating women completed $24 \mathrm{~h}$ dietary recall food intake. 


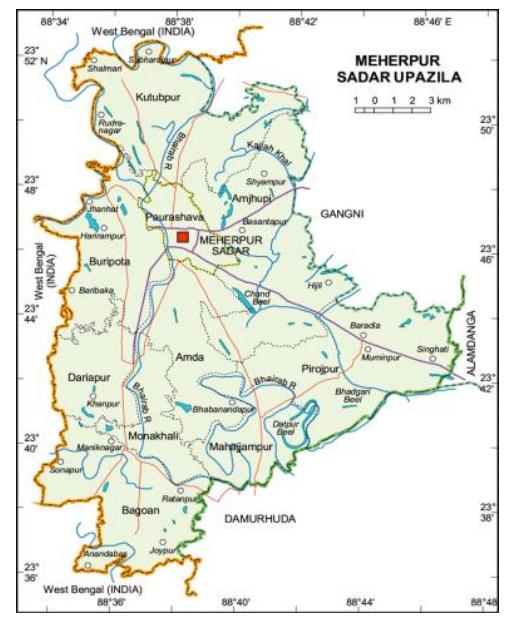

Figure 1. Map of Gangni union of Meherpur district showing the study area.

\subsection{Study design}

The study was cross-sectional in design and 24-hour recall method and 7-day food frequency questionnaire were used for assessing dietary consumption pattern as well as dietary diversity of the targeted population group from the pre-selected households.

\subsection{Study population}

The study households were selected purposively from the list of households that were previously selected in consultation with household level. Personal interviews were conducted to collect a $24 \mathrm{~h}$ diet recall questionnaire from 105 lactating women.

\subsection{Data collection}

After arrival at the selected district, first step was to locate the selected villages having higher number of lactating mothers. Mapping of the villages was done with the help of local people. Then pre-tested questionnaire, based on 24-hour recall method was applied to collect dietary information. Primary respondent was the female members of the households including lactating mothers. The respondents were asked to recall all food items that they had consumed on the last day prior to the interview.

\subsubsection{Socio-demographic characteristics}

A structured questionnaire was used to obtain information on socio-demographic characteristics of the subjects such as age, occupation, education, income, number of children, household size.

\subsubsection{Anthropometric measurements}

Weight measurement was taken using a portable bathroom scale. The subjects were asked to remove any clothing which might change body weight and remove their shoes while standing erect on the weighing scale. Readings were taken to the nearest $0.1 \mathrm{~kg}$. Height was measured using a portable height to meter with a movable head piece while subjects stood erect on bare foot. Measurement was taken to the nearest $0.1 \mathrm{~cm}$. BMI was calculated as weight $(\mathrm{kg})$ divided by height $\left(\mathrm{m}^{2}\right)$ for each subject (Table 1). All measurements were taken and recorded in duplicates using standard procedures.

\section{Table 1. Classification of BMI according to WHO.}

\begin{tabular}{ll}
\hline Body Mass Index (BMI) & Nutritional Status \\
\hline Below 16 & Chronic under nutrition \\
$16-17.49$ & Severe under nutrition \\
$17.5-18.49$ & Under nutrition \\
$18.5-24.99$ & Normal weight \\
$25-29.99$ & Over weight \\
$30-34.99$ & Mild obesity \\
$35-39.99$ & Moderate obesity \\
More than 40 & Several obesity \\
\hline
\end{tabular}




\subsubsection{Twenty four hour dietary recall}

The dietary interview is comprised of two sections: the Dietary Recall section and the Post Recall section. The Dietary Recall section includes the 24-hour dietary recall and a set of health related and data retrieval questions. The Post-Recall section includes fish/shellfish questions, food security questions, and questions about the recent health of child SPs. The 24-hour dietary recall collects a list of all the foods and beverages an SP consumed within a 24-hour period; the time of consumption and the name of the eating occasion; detailed food descriptions and amounts of the reported foods; where it was obtained; and whether it was eaten at home or not. The recall is followed by a set of health-related questions. The data will be collected using the new USDA AMPM instrument. Information collected from the 24-hour dietary recall will be coded and linked to a database of foods and their nutrient composition. Calculation of total daily nutrient intakes will be derived from the data. The information obtained will be used to describe the food and nutrient intake of the population.

\subsection{Data management and analysis}

All completed questionnaires were checked for inconsistency and errors by the supervisor before computerization. A coding manual and data entry layout was prepared and thereafter data were entered using the SPSS 16.0 version software.

\section{Results}

\subsection{Basic information of the respondents}

It was found that, 105 households in Meherpur District. Total number of participated lactating mother is 105 (Table 2).

Table 2. Background information of the respondents from the surveyed households.

\begin{tabular}{ll}
\hline District & Meherpur \\
\hline No of surveyed household & 105 \\
No of participated lactating mother & 105 \\
No of missing lactating mother & 0 \\
\hline
\end{tabular}

\subsection{Socio-economic characteristics of the respondents}

About $16.2 \%$ lactating mothers were under 19 years, 53.3\% respondents were between the ages of 20-25 years, $23.8 \%$ respondents were between the ages of $26-30$ years and $6.7 \%$ respondents age over 30 years (Table 3 ).

Table 3. Percentage distribution of respondents according to their age group.

\begin{tabular}{lll}
\hline Age & Respondents & Percentages $(\%)$ \\
\hline$<19$ & 17 & $16.2 \%$ \\
$20-25$ & 56 & $53.3 \%$ \\
$26-30$ & 25 & $23.8 \%$ \\
$>30$ & 7 & $6.7 \%$ \\
Total & $\mathbf{1 0 5}$ & $\mathbf{1 0 0 . 0 \%}$ \\
\hline
\end{tabular}

\subsubsection{Educational status}

About $37.1 \%$ lactating mothers had completed primary education, only $1.9 \%$ had not completed primary education. About $22.9 \%$ had acquired secondary education, $22.9 \%$ had acquired secondary education and about $15.2 \%$ had acquired graduate and above (Table 4$)$.

Table 4. Percentage distribution of respondents according to their educational status.

\begin{tabular}{lll}
\hline Educational Status of Respondent & Respondent & Percentages (\%) \\
\hline Illiterate & 2 & $1.9 \%$ \\
Primary & 39 & $37.1 \%$ \\
Secondary & 24 & $22.9 \%$ \\
Higher secondary & 24 & $22.9 \%$ \\
Graduate \& above & 16 & $15.2 \%$ \\
Total & $\mathbf{1 0 5}$ & $\mathbf{1 0 0 . 0 \%}$ \\
\hline
\end{tabular}




\subsubsection{Occupation}

The occupation of participant lactating mothers was divided into two groups: housewife and service holders. About $95.2 \%$ respondents were housewife and $4.8 \%$ respondents were service holders (Table 5).

Table 5. Percentage distribution of respondents according to their occupation.

\begin{tabular}{lll}
\hline Occupation of mother & Respondent & Percentages (\%) \\
\hline Housewife & 100 & $95.2 \%$ \\
Service holder & 5 & $4.8 \%$ \\
Total & $\mathbf{1 0 5}$ & $\mathbf{1 0 0 . 0 \%}$ \\
\hline
\end{tabular}

\subsubsection{Number of children}

About $56.2 \%$ respondents have 1 child, $37.1 \%$ respondents have 2 children and $6.7 \%$ respondents have 3 or more children (Table 6).

Table 6. Percentage distribution of respondents according to their number of children.

\begin{tabular}{lll}
\hline Number of children & Respondent & Percentages (\%) \\
\hline 1 & 59 & $56.2 \%$ \\
2 & 39 & $37.1 \%$ \\
3 and above & 7 & $6.7 \%$ \\
Total & $\mathbf{1 0 5}$ & $\mathbf{1 0 0 . 0 \%}$ \\
\hline
\end{tabular}

\subsubsection{Family Members}

About $38.1 \%$ respondents have 3 family members, $43.8 \%$ respondent have 4 family members where $18.1 \%$ respondents have 5 family members (Table 7).

Table 7. Percentage distribution of respondents according to their family members.

\begin{tabular}{lll}
\hline Family members & Respondent & Percentages (\%) \\
\hline 3 & 40 & $38.1 \%$ \\
4 & 46 & $43.8 \%$ \\
5 & 19 & $18.1 \%$ \\
Total & $\mathbf{1 0 5}$ & $\mathbf{1 0 0 . 0 \%}$ \\
\hline
\end{tabular}

\subsubsection{Husband's occupation}

About $27.6 \%$ were service holder, about $26.7 \%$ were businessmen, $13.3 \%$ were farmer, $19.0 \%$ were day labor and $13.3 \%$ were other occupation (Table 8).

Table 8. Percentage distribution of respondents according to their husband's occupation.

\begin{tabular}{lll}
\hline Husbands occupation & Respondent & Percentages (\%) \\
\hline Service holder & 29 & $27.6 \%$ \\
Business & 28 & $26.7 \%$ \\
Farmer & 14 & $13.3 \%$ \\
Day labor & 20 & $19.0 \%$ \\
Others & 14 & $13.3 \%$ \\
Total & $\mathbf{1 0 5}$ & $\mathbf{1 0 0 . 0 \%}$ \\
\hline
\end{tabular}

\subsubsection{Family income per month}

About 3.8\% respondents family income were $<5000$. 26.7\% income range were 5000-10000, 36.2\% income range were 10000-20000, and 33.3\% income range were $>20000$ (Table 9). 
Table 9. Percentage distribution of respondents according to their family income per months.

\begin{tabular}{lll}
\hline Family income per month & Respondent & Percentages $(\boldsymbol{\%})$ \\
\hline$<5000$ & 4 & $3.8 \%$ \\
$5000-10000$ & 28 & $26.7 \%$ \\
$10000-20000$ & 38 & $36.2 \%$ \\
$20000+$ & 35 & $33.3 \%$ \\
Total & $\mathbf{1 0 5}$ & $\mathbf{1 0 0 . 0 \%}$ \\
\hline
\end{tabular}

3.3. Nutritional status of lactating mothers

\subsubsection{Body mass index (BMI)}

About $7.6 \%$ respondents are underweight, 55.2\% respondents are normal, 33.3\% respondents are overweight and $3.8 \%$ respondents are obese (Table 10 ).

Table 10. Percentage distribution of respondent's body mass index (BMI).

\begin{tabular}{lll}
\hline Body mass index (bmi) & Respondents & Percentages (\%) \\
\hline Underweight & 8 & $7.6 \%$ \\
Normal & 58 & $55.2 \%$ \\
Overweight & 35 & $33.3 \%$ \\
Obese & 4 & $3.8 \%$ \\
Total & $\mathbf{1 0 5}$ & $\mathbf{1 0 0 . 0 \%}$ \\
\hline
\end{tabular}

3.4. Comparison of family income and age specific BMI of lactating mothers.

3.4.1. Ages range according to body mass index (BMI)

Total 7.6\% respondents are underweight, 55.2\% respondents are normal, 33.3\% respondents are overweight and $3.8 \%$ respondents are obese where 5.7\% respondents under 19 year aged and $1.9 \%$ respondents over 30 year aged are underweight, $10.5 \%$ respondents under 19 year aged, $25.7 \%$ respondents $20-25$ year aged are $19.0 \%$ respondents 26-30 year aged are normal, 25.7\% respondents 20-25 years aged, 4.8\% respondents 26-30 years aged and 2.9\% respondents over 30 years aged are overweight, $1.9 \%$ respondents $20-25$ years aged and $1.9 \%$ respondents over 30 years aged are obese (Table 11).

Table 11. Percentage distribution of respondents ages range according to body mass index.

\begin{tabular}{|c|c|c|c|c|c|}
\hline \multirow[t]{2}{*}{ Body mass index (BMI) } & \multicolumn{4}{|c|}{ Age range of respondents } & \multirow[t]{2}{*}{ Total } \\
\hline & $<19$ yrs & 20-25yrs & 26-30yrs & $>30 y r s$ & \\
\hline Underweight & $5.7 \%(6)$ & $0.0 \%(0)$ & $0.0 \%(0)$ & $1.9 \%(2)$ & $7.6 \%(8)$ \\
\hline Normal & $10.5 \%(11)$ & $25.7 \%(27)$ & $19.0 \%(20)$ & $0.0 \%(0)$ & $55.2 \%(58)$ \\
\hline Overweight & $0.0 \%(0)$ & $25.7 \%(27)$ & $4.8 \%(5)$ & $2.9 \%(3)$ & $33.3 \%(35)$ \\
\hline Obese & $0.0 \%(0)$ & $1.9 \%(2)$ & $0.0 \%(0)$ & $1.9 \%(2)$ & $3.8 \%(4)$ \\
\hline Total & $16.2 \%(17)$ & $53.3 \%(56)$ & $23.8 \%(25)$ & $6.7 \%(7)$ & $100.0 \%(105)$ \\
\hline
\end{tabular}

3.4.2. Body mass index (BMI) according to family income per month

total 7.6\% respondents are underweight, 55.2\% respondents are normal, 33.3\% respondents are overweight and $3.8 \%$ respondents are obese where $4.8 \%$ respondents family income range from 5000-10000 and $2.9 \%$ respondents over 20000 are underweight, 3.8\% respondents family income under 5000, $14.3 \%$ respondents 5000-10000, 20\% respondents 10000-20000 are normal, 7.6\% respondents family income range from 5000$10000,12.4 \%$ respondents $10000-20000$ and $13.3 \%$ respondents over 20000 are overweight, $3.8 \%$ respondents family income range from 10000-20000 are obese (Table 12). 
Table 12. Percentage distribution of respondents Body Mass Index (BMI) according to family income per month.

\begin{tabular}{llllll}
\hline Body Mass Index (BMI) & \multicolumn{4}{c}{ Family income per month } & Total \\
\cline { 2 - 5 } & $\mathbf{< 5 0 0 0}$ & $\mathbf{5 0 0 0 - 1 0 0 0 0}$ & $\mathbf{1 0 0 0 0 - 2 0 0 0 0}$ & $\mathbf{2 0 0 0 0 +}$ & \\
\hline Underweight & $.0 \%(0)$ & $4.8 \%(5)$ & $.0 \%(0)$ & $2.9 \%(3)$ & $7.6 \%(8)$ \\
Normal & $3.8 \%(4)$ & $14.3 \%(15)$ & $20.0 \%(21)$ & $17.1 \%(18)$ & $55.2 \%(58)$ \\
Overweight & $.0 \%(0)$ & $7.6 \%(8)$ & $12.4 \%(13)$ & $13.3 \%(14)$ & $33.3 \%(35)$ \\
Obese & $.0 \%(0)$ & $.0 \%(0)$ & $3.8 \%(4)$ & $.0 \%(0)$ & $3.8 \%(4)$ \\
Total & $\mathbf{3 . 8 \% ( 4 )}$ & $\mathbf{2 6 . 7 \% ( 2 8 )}$ & $\mathbf{3 6 . 2 \% ( 3 8 )}$ & $\mathbf{3 3 . 3 \%}(\mathbf{3 5})$ & $\mathbf{1 0 0 \%}(\mathbf{1 0 5})$ \\
\hline
\end{tabular}

3.5. General knowledge, practices and hygeinity practices of lactating mothers

3.5.1. Birth delivery status

About $40 \%$ respondents got surgerian delivery where $60 \%$ respondents got normal delivery (Table 13).

Table 13. Percentage distribution of respondents according to their delivery status.

\begin{tabular}{lll}
\hline Surgerian or normal & Respondents & Percentages (\%) \\
\hline Surgerian & 42 & $40.0 \%$ \\
Normal & 63 & $60.0 \%$ \\
Total & $\mathbf{1 0 5}$ & $\mathbf{1 0 0 . 0 \%}$ \\
\hline
\end{tabular}

\subsubsection{Physical activity}

The Physical Activity of participant lactating mothers. 2.9\% respondent ware moderate worker and $97.1 \%$ respondent were primary workers (Table 14).

Table 14. Percentage distribution of respondents according to their physical activity.

\begin{tabular}{lll}
\hline Physical Activity & Respondent & Percentages (\%) \\
\hline Moderate & 3 & $2.9 \%$ \\
Primary & 102 & $97.1 \%$ \\
Total & $\mathbf{1 0 5}$ & $\mathbf{1 0 0 . 0 \%}$ \\
\hline
\end{tabular}

3.5.3. Knowledge about importance of colostrum

About $68.6 \%$ respondents were known about the importance of colostrum and $31.4 \%$ respondents were unaware (Table 15).

Table 15. Percentage distribution of respondents about the importance of colostrum.

\begin{tabular}{lll}
\hline Knowledge about importance of colostrum & Respondents & Percentages (\%) \\
\hline Yes & 72 & $68.6 \%$ \\
No & 33 & $31.4 \%$ \\
Total & $\mathbf{1 0 5}$ & $\mathbf{1 0 0 . 0 \%}$ \\
\hline
\end{tabular}

3.5.4. Knowledge about early initiation of breastfeeding after birth

About $94.3 \%$ respondents were known about the importance of early initiation of breastfeeding and 5.7\% were unaware (Table 16).

Table 16. Percentage distribution of respondents about the importance of early initiation of breastfeeding after birth.

\begin{tabular}{lll}
\hline Knowledge about early initiation of breastfeeding after birth & Frequency & Percentages (\%) \\
\hline Yes & 99 & $94.3 \%$ \\
No & 6 & $5.7 \%$ \\
Total & $\mathbf{1 0 5}$ & $\mathbf{1 0 0 . 0 \%}$ \\
\hline
\end{tabular}


3.5.5. Knowledge about importance of exclusive breastfeeding

About $90.5 \%$ respondents were known about the importance of exclusive breastfeeding and $9.5 \%$ respondents were unaware (Table 17).

Table 17. Percentage distribution of respondents about the importance of exclusive breastfeeding.

\begin{tabular}{lll}
\hline Knowledge about importance of exclusive breastfeeding & Frequency & Percentages (\%) \\
\hline Yes & 95 & $90.5 \%$ \\
No & 10 & $9.5 \%$ \\
Total & $\mathbf{1 0 5}$ & $\mathbf{1 0 0 . 0 \%}$ \\
\hline
\end{tabular}

\subsubsection{Knowledge about foods for baby after 6 months}

$100 \%$ respondents were known of which foods are needed for the baby after 6 months (Table 18).

Table 18. Percentage distribution of respondent knowledge about foods for baby after 6 months.

\begin{tabular}{lll}
\hline Knowledge about foods for baby after $\mathbf{6}$ months & Respondents & Percentages (\%) \\
\hline Yes & 105 & $100.0 \%$ \\
No & 0 & $0.00 \%$ \\
Total & $\mathbf{1 0 5}$ & $\mathbf{1 0 0 . 0 \%}$ \\
\hline
\end{tabular}

\subsubsection{Hygiene practices}

Here, $100 \%$ respondents maintain hygiene such as washing hands before eating foods, washing hands after using bathroom, brushing teeth regularly, avoiding nasty foods etc (Table 19).

Table 19. Percentage distribution of respondents according to hygiene practices.

\begin{tabular}{|c|c|c|c|}
\hline \multirow[t]{2}{*}{ Hygiene practices } & \multicolumn{2}{|c|}{ Respondents } & \multirow[t]{2}{*}{ Percentages (\%) } \\
\hline & Yes & No & \\
\hline Avoiding nasty foods & 105 & 0 & $100.0 \%$ \\
\hline Washing hand before eating & 105 & 0 & $100.0 \%$ \\
\hline Washing hand after using bathroom & 105 & 0 & $100.0 \%$ \\
\hline Brushing teeth regularly & 105 & 0 & $100.0 \%$ \\
\hline
\end{tabular}

\section{Discussion}

The study was assessed to give a situation of lactating mother's nutritional status and associated factors in rural Bangladesh. The nutritional status of lactating mother was measured by Body Mass Index (BMI), weight in kilogram divided by height square in meter, based on WHO standard classification. Out of the total participants measurement had taken most of them were in the normal BMI range $58(55.2 \%)$, that is from $18.5-24.9 \mathrm{~kg} / \mathrm{m}^{2}$. One third of the study participants $35(33.3 \%)$ had BMI from $25-29.9 \mathrm{~kg} / \mathrm{m}^{2}$ which were overweight. Whereas eight $(7.6 \%)$ of participants were underweight with BMI less than $18.5 \mathrm{~kg} / \mathrm{m}^{2}$ and $4(3.8 \%)$ of them had BMI of greater than thirty which were obsess. This indicates that the prevalence of underweight was significant which was found to be similar with the finding of Darussalam, 21.2\% underweight, (WFP and UNICEF, 2010). This is may be attributed to the impact of socio -demographic factors such as family income, family size, husband education, occupation status of mother and nutritional information which may contributed to the incidence of dietary inadequacies. On the other hand compared to similar study in Mekele, Ethiopia the underweight in Nekemte was lower, 25\% (Haileslassie et al., 2013). This study revealed that family income has a due effect on the nutritional status of lactate mother. Those mothers who have monthly family income 5000-10000 were less likely exposed to underweight. This finding is similar with the UNICEF study on lactate mothers (UNICEF, 2010). This indicates that household economic status is positively associated with maternal nutrition status, which is a pre-requisite for access to adequate dietary intake and improved nutritional status for members of maternal nutritional status. In developing countries, it has been reported that the income of a household is an important determinant of its access to food which in turn is a major determinant of child and maternal nutrition and wellbeing (Miller et al., 2005). Epidemiological studies have reported on the relationship between diet and poverty; and the report established that the purchasing power of a family indicates the level of household food security and types of diets that are ultimately consumed by household members (Kirna, 2005). Occupational is also another important socioeconomic variable explaining nutritional status. According this study, employment 
of women was a significant factor for nutritional status of mothers as compared with mother employment. House wife and unemployed mothers were more vulnerable to under nutrition than service holder or other occupation mothers. The probable reason for this could be that House wife and unemployed mother workers have lower educational status than mothers working employed (EDHS, 2005) and they have relatively less decision-making autonomy and less control over income than women with governmental employers. Women's paid employment could provide an additional income source that can improve food security of the household and raise the status of women by allowing them to have more control over resources. Some evidence also indicates that the nutritional impact of increased household income is a function of the income earner and the kind of income (ACC/SCN, 2003). This founding was similar with that unemployed women were at high risk of under nutrition, even in households with a relatively better socioeconomic status. On the hand husband education and nutritional information are other factors that significantly associate to nutritional status of lactate mother. Regarding husband education, those families whose husband had minimum of primary education were less likely exposed to under nutrition. The finding of the study stated that individuals with a higher educational level had better nutrition knowledge and higher nutrition knowledge of employed women in study area. As can be seen in the multivariate logistic regression analysis identified family income, family size and definition of food as the most determinant factors of nutritional status of lactating mother. The sample showed that, as compared to low monthly income ( $<1000$ birr) family the high monthly income family lactating mothers were almost 0.25 less likely vulnerable to under nutrition. The study also showed that lactating mothers who have knowledge of food were less likely develops under nutrition.

\section{Conclusions}

The present findings uncovered information on the nutritional status, and associated factors among lactating mothers in selected areas. This study revealed that the prevalence of underweight, normal, overweight and obesity were $8(\%), 240(75 \%), 15(4.7)$ and 5(0.3\%), respectively. From the finding of this study, it can be also concluded that low income lactate mothers have the highest rates of underweight. From multiple logistic regression analysis the common determinant factors that significantly affect nutritional status of lactating mothers were family size and family income. However, other predictable variables like age, marital status, culture, ethnicity, religion, husband occupation, and nutritional information have no association with nutritional status of lactating mothers. Proper family planning and the way that lactating mothers increase their income should be designed by concerned body.

\section{Conflict of interest}

None to declare.

\section{References}

ACC/SCN, 2003. Annual United Nations SCN (Standing Committee on Nutrition) conference was held in Chennai, India. Key achievements and plans to emerge from the nutrition in emergencies working group.

Allen LH, 2012. B vitamins in breast milk: relative importance of maternal status and intake, and effects on infant status and function. Adv. Nutr., 3: 362-369.

Bangladesh Bureau of Statistics (BBS), 2003. Report of the Household Income and Expenditure Survey 2000. Dhaka: BBS, Statistics Division, Ministry of Planning, Government Republic of Bangladesh.

Bates CJ, AM Prentice, M Watkinson, P Morrell, BA Sutcliffe, FA Foord and RG Whitehead, 1982. Riboflavin requirements of lactating Gambian women: A controlled supplementation trial. Am. J. Clin. Nutr., 35: 701-709.

Chasnyk VG, SL Avrusin, VI Asaulenko, VN Shepovalnikov, VA Onoskho and SB Teshebeav, 2011. Methodology and results of prophylactic examination of children. In: Degteva GN, editor. Problems of healthcare and social development of Russian Arctic. Saint-Petersburg: Paulsen, 7: 373-391.

Cheng Y, MJ Dibley, X Zhang, L Zeng and H Yan, 2009. Assessment of dietary intake among pregnant women in a rural area of western China. BMC Public Health, 9: 222.

Dang S, H Yan and S Yamamoto, 2008. High altitude and early childhood growth retardation: new evidence from Tibet. Eur. J. Clin. Nutr., 62: 342-348.

Giashuddin MS, M Kabir, A Rahman and MA Hannan, 2003. Exclusive breastfeeding and nutritional status in Bangladesh. Indian J. Pediatr., 70: 471-475.

Guesnet P and JM Alessandri, 2011. Docosahexaenoic acid (DHA) and the developing central nervous system (CNS)Implications for dietary recommendations. Biochimie, 93: 7-12.

Gunderson EP, DR Jacobs, Chiang V, CE Lewis, J Feng, CP Quesenberry and S Sidney, 2010. Duration of lactation and incidence of the metabolic syndrome in women of reproductive age according to gestational diabetes mellitus status: a 20-Year prospective study in CARDIA (Coronary artery risk development in young adults). Diabetes, 59: $495-504$. 
Haileslassie K, A Mulugeta and M Girma, 2013. Feeding practices, nutritional status and associated factors of lactating women in SamreWoreda, South Eastern Zone of Tigray, Ethiopia. Nutrition Journal, 12: 28-35.

Haskell MJ and KH Brown, 1999. Maternal vitamin A nutriture and the vitamin A content of human milk. Journal of Mammary Gland Biology and Neoplasia, 4: 243-257.

Hollis BW and CL Wagner, 2004. Vitamin D requirements during lactation: high-dose maternal supplementation as therapy to prevent hypo-vitaminosis D for both the mother and the nursing infant. Am. J. Clin. Nutr., 80: 1752S-1758S.

Ijarotimi OS, 2010. Assessing exclusive breastfeeding practices, dietary intakes and body mass index (BMI) of nursing mothers in Ekiti State of Nigeria. Nutrition Research and Practice, 4: 222-228.

Jones KD, JA Berkley and JO Warner, 2010. Perinatal nutrition and immunity to infection. Pediatric Allergy and Immunology, 21: 564-576.

Kinra S, RP Nelder and GJ Lewendon, 2005. Deprivation and childhood obesity: a cross sectional study of maternal nutrition and pregnancy outcomes, $4: 36-39$.

Lönnerdal BO, 1986. Effects of maternal dietary intake on human milk composition. J. Nutr., 116: 499-513.

Makrides M, MA Neumann and RA Gibson, 1996.Effect of maternal docosahexaenoic acid (DHA) supplementation on breast milk composition. Eur. J. Clin. Nutr., 50: 352-357.

Marcos A, E Nova and A Montero, 2003. Changes in the immune system are conditioned by nutrition. Eur. J. Clin. Nutr., 57: S66-S69.

Mulligan ML, SK Felton, AE Riek and C Bernal-Mizrachi, 2010. Implication of vitamin D deficiency in pregnancy and lactation. Am. J. Obstet. Gynecol., 202: e421-e429.

Paul AM, 2010. How the first nine months shape the rest of your life. Time Magazine, 22.

Picciano MF, 2001. Nutrient composition of human milk. Pediatric Clinics of North America, 48: 53-67.

Rakibul I and AS Mashhood, 2010. Cultural and socio-economic factors in health, health services and prevention for indigenous people. Antrocom Online Journal of Anthropology, 6: 263-273.

Rasmussen KM and MK McGuire, 1996. Effects of breastfeeding on maternal health and well-being. Food and Nutrition Bulletin, 17: 366-370.

Salamat-Miller N, M Chittchang and TP Johnston, 2005. The use of mucoadhesive polymers in buccal drug delivery. Adv. Drug Deliv. Rev., 57: 1666-1691.

Sanusi RA and OA Falana, 2013. The Nutritional Status of Mothers Practicing Breast Feeding In Ibadan, Nigeria. Afr. J. Biomed. Res., 12: 107-112.

Schwarz EB, RM Ray, AMStuebe, MA Allison, RB Ness, MS Freiberg and JA Cauley, 2009. Duration of lactation and risk factors for maternal cardiovascular disease. Obstetrics and Gynecology, 113: 974-985.

Scopesi F, S Ciangherotti, PB Lantieri, D Risso, I Bertini, F Campone and G Serra, 2001. Maternal dietary PUFAs intake and human milk content relationships during the first month of lactation. Clinical Nutrition, 20: 393-397.

Stuebe AM, JW Rich-Edwards, WC Willett, JE Manson and KB Michels, 2005. Duration of lactation and incidence of type 2 diabetes. JAMA, 294: 2601-2610.

StuebeAM, K Kleinman, MW Gillman, SL Rifas-Shiman, EP Gunderson and J Rich-Edwards, 2010. Duration of lactation and maternal metabolism at 3 years postpartum. Journal of Women's Health, 19: 941-950.

Stuebe AM, WC Willett, F Xue and KB Michels, 2009. Lactation and incidence of premenopausal breast cancer: a longitudinal study. Arch. Intern. Med., 169: 1364-1371.

Sylvia B and DS Mary, 2002. The Nursing Mother's Diet. The art of successful breastfeeding: A Mother's Guide.

Takimoto H, N Yoshiike, A Katagiri, H Ishida and S Abe, 2003. Nutritional status of pregnant and lactating women in Japan: a comparison with nonpregnant/ non-lactating controls in the National Nutrition Survey. J. Obstet. Gynaecol. Res., 29: 96-103.

The 2005 Ethiopia Demographic and Health Survey (EDHS), 2005. Worldwide MEASURE DHS project which is funded by the United States Agency for International Development (USAID). The opinions expressed herein are those of the authors and do not necessarily reflect the views of USAID.

Ukegbu PO and AC Uwaegbute, 2012. Body composition changes among lactating mothers in Abia State, Nigeria. Am. J. Food. Nutr., 2: 21-25.

WFP and UNICEF, 2010. Comprehensive food and nutrition security and vulnerability analysis. United Nation head quarter, New York.

Whitehead RG, 1979. Nutrition and lactation. Postgraduate Medical Journal, 55: 303-310. 